\title{
SCIENTIFIC REPORTS

\section{In utero elemental tags in vertebrae of the scalloped hammerhead shark Sphyrna lewini reveal migration patterns of pregnant females}

\author{
Claire Coiraton $\mathbb{1 D}^{1}$ \& Felipe Amezcua ${ }^{2 *}$
}

Vertebral microchemistry recently allowed to infer the migration patterns of the scalloped hammerhead shark Sphyrna lewini in the Mexican Pacific, however conclusions regarding the movements of reproductive females were hindered by the small sample size. Considering that $S$. lewini is a placental viviparous species, maternal supply of nutrients to the embryos might influence their vertebral microchemistry while in utero and provide intrinsic markers of the pregnant female environmental histories. This hypothesis was tested before attempting to infer the migration patterns of pregnant females through the analyses of the in utero elemental profiles quantified in the vertebrae of coastal young-of-the-year ('YOY'). Vertebrae were obtained from sharks captured along the Mexican Pacific coast in 2016. Vertebral microchemistry was quantified using laser ablation inductively-coupled plasma mass spectrometry. Elemental signatures at vertebral edge were consistent between each pregnant female and her embryos demonstrating the viability of employing in utero elemental signatures as a maternal tag of the gestation-related environmental histories. Analyses of the YOY in utero $\mathrm{Sr}: \mathrm{Ba}$ and $\mathrm{Pb}$ :Ca profiles suggested that pregnant females either (1) progressively migrated offshore before quickly returning to coastal habitats before term or (2) remained nearshore during complete gestation. Considering the endangered status of $S$. lewini, current management measures may be insufficient for the sustainable management of the population as pregnant females may be particularly susceptible to fisheries when remaining nearshore or entering coastal habitats prior to pupping.

The scalloped hammerhead shark, Sphyrna lewini (Griffith and Smith 1834), is a circumtropical migratory species that uses both oceanic and coastal habitats for its dispersal and reproductive strategy ${ }^{1}$. In the Mexican Pacific, neonate and juvenile stages of S. lewini are typically found in shallow estuarine and coastal habitats ${ }^{2-4}$ for their first 3 to 7 years of life $\mathrm{f}^{5-7}$ before migrating offshore to maximize their foraging opportunities and grow more rapidly to reproductive size ${ }^{5}$. Adults, on the other hand, seasonally form schools near seamounts and oceanic islands ${ }^{8-10}$ and females later return to coastal habitats for parturition (possibly annually ${ }^{11,12}$ ). Although males do not have such requirement, recent studies indicated that some individuals may also later return to coastal habitats or even remain nearshore for their entire life ${ }^{7,13}$, thus being able to mate opportunistically with females entering coastal waters to give birth ${ }^{13-15}$. Though these findings provided more insights into the life history of males, the present state of knowledge on the migratory patterns of females remains fragmentary, particularly during the gestation.

Microchemical signatures derived from elements deposited in the vertebrae of sharks during growth can reflect changes in the surrounding water chemistry ${ }^{16-19}$, environmental conditions ${ }^{16,18,20}$ and diet ${ }^{21,22}$, and thus serve as discrete site-specific markers ${ }^{19,23-27}$ or time-resolved records of the individual environmental histories when related to growth bands $7,17,19,20,28$. More specifically, it was recently showed that vertebral microchemistry of the scalloped hammerhead shark S. lewini could accurately distinguish among individuals from different locations of the Mexican Pacific, whether these had been occupying coastal or more oceanic habitats, and address important questions concerning the recent habitat use and natal origin ${ }^{7,23}$ of the species in the region.

${ }^{1}$ Posgrado en Ciencias del Mar y Limnología, Universidad Nacional Autónoma de México; Av. Ciudad Universitaria 3000, Coyoacán, Mexico City, 04510, Mexico. ${ }^{2}$ Instituto de Ciencias del Mar y Limnología, Universidad Nacional Autónoma de México. Av. Joel Montes Camarena s/n, Mazatlán 82040, Sinaloa, Mexico. *email: famezcua@ola. icmyl.unam.mx 


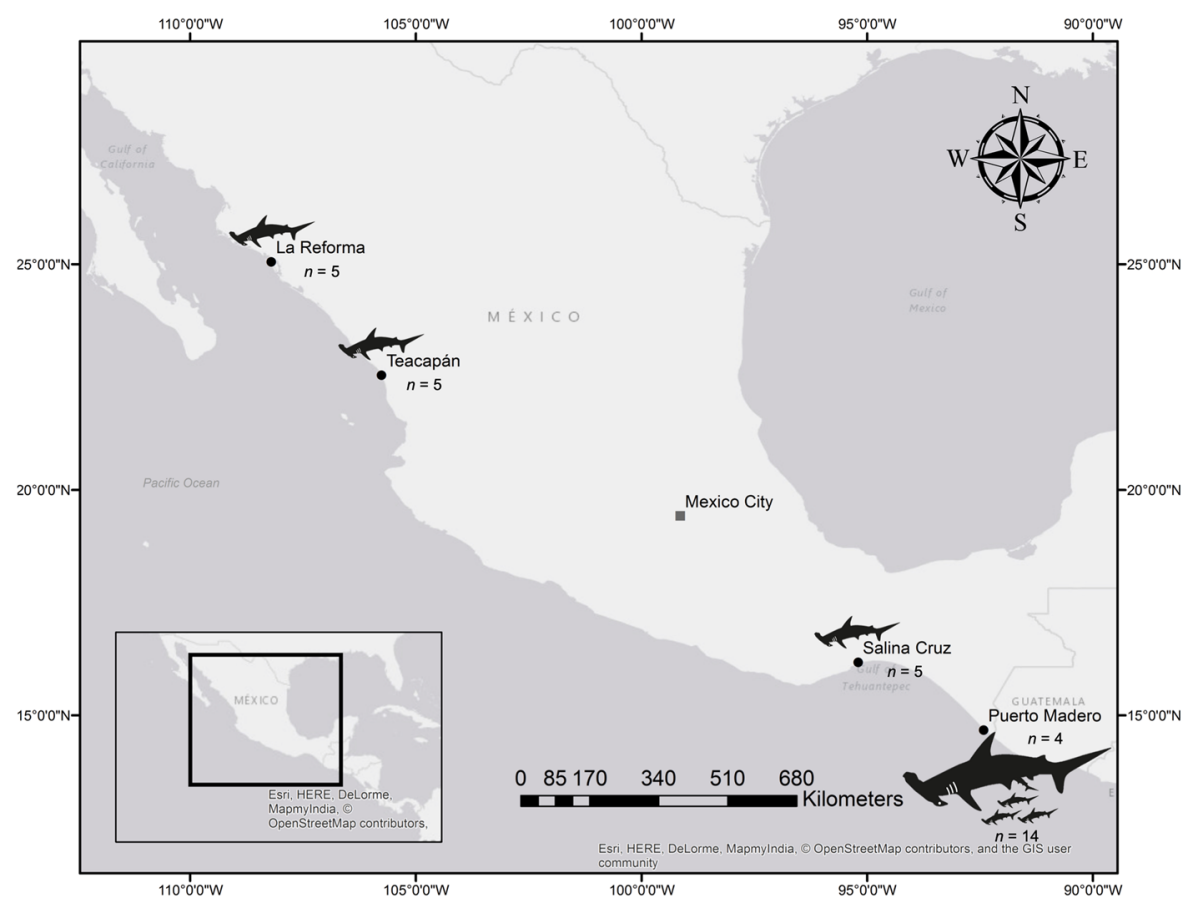

Figure 1. Map of the region of study showing the sampling sites of pregnant females $(n=4)$, embryos $(n=14)$ and young-of-the-year $(n=15)$ specimens of Sphyrna lewini in the Mexican Pacific (hammerhead illustrations used with permission (CFlora pixelia).

Concentrations of strontium ${ }^{88} \mathrm{Sr}$, barium ${ }^{137} \mathrm{Ba}$ and lead ${ }^{208} \mathrm{~Pb}$ were assessed along vertebral transects encompassing complete life histories, which allowed to document several aspects on the migratory patterns of S. lewini because these elements were found to reflect the nearshore-offshore movements of the sharks across the apparent salinity gradient $t^{7,17,19,29}$ and periods of nearshore residency into contaminated habitats ${ }^{7,30-32}$. Robust conclusions regarding the migration patterns of females, and particularly mature individuals, were however hindered by the small sample size and the lack of discernible pattern in the age-related elemental profiles for some individuals ${ }^{7}$.

As a placental viviparous species, S. lewini exhibits high degree of maternal investment in its offspring. During their first weeks of development, embryos derive their nourishment from their yolk-sacs after which these transform to become a highly vascularized placenta that directly provides nutrients to the embryos through the mother's blood stream ${ }^{33}$. Given the long gestation period of S. lewini (i.e. 10-11 months $\mathrm{s}^{11,12}$ ), maternal supply of nutrients to embryos has the potential to influence the vertebral microchemistry of embryos while in utero ${ }^{7}$, at least after placental formation ${ }^{34}$. Accordingly, validating the relationships between maternal vertebral microchemistry and elemental composition of embryos may provide novel proxies for inferring the migration patterns of pregnant females and facilitate further investigations on the species population connectivity through the examination of in utero elemental signatures or transect profiles quantified in the vertebrae of coastal juvenile stages ${ }^{7}$, that are a more frequent component of the small-scale fisheries operating along the Mexican Pacific coast when compared to pregnant females ${ }^{2,3,35}$.

The objective of this study was to establish the viability of employing the in utero elemental signatures deposited in vertebrae of S. lewini as intrinsic markers of the environmental histories of pregnant females during their gestation in the Mexican Pacific. More specifically, this study sought to test the hypotheses that: (1) elemental signatures in vertebrae and (2) elemental profiles encompassing complete in utero development were consistent among embryos within each pregnant female's litter and (3) vertebral microchemistry of embryos reflected that of pregnant females during the gestation in order to (4) attempt to assess the gestation-related movements of pregnant females using in utero maternal tags in the vertebrae of coastal juveniles. Only young-of-the-year specimens (age 0 ) were considered to avoid potential site-specific temporal variations in the water chemistry that might result in different elemental signatures for individuals of different ages originating from the same nurseries ${ }^{23}$.

\section{Material and Methods}

Sample collection. Vertebrae samples from pregnant females of S. lewini and their embryos were obtained from specimens captured in April 2016 by the artisanal shark fishery operating off Puerto Madero (Fig. 1; Table 1). Vertebrae samples from young-of-the-year specimens were obtained between August and October 2016 from three artisanal fishery landings along the Mexican Pacific coast, in La Reforma, Teacapán and Salina Cruz (Fig. 1; Table 2). These sampling locations were selected to address the questions of this study because they were reported as important nursery areas for S. lewini in the Mexican Pacific ${ }^{2-4,11,36,37}$. Fishers used surface and bottom gillnets and surface longlines. All sample collection was opportunistic and carried out in accordance with relevant national guidelines and regulations. Sex and total length $\left(L_{\mathrm{T}}\right)$ were recorded for each specimen and a set of post-cephalic vertebrae was removed and stored frozen until preparation for analyses. 


\begin{tabular}{|l|l|l|l|}
\hline $\begin{array}{l}\text { Female's litter } \\
\text { code }\end{array}$ & $\boldsymbol{L}_{\text {T females }}$ & $\boldsymbol{n}_{\text {embryos }}$ & $\boldsymbol{L}_{\text {T embryos }}$ \\
\hline 1 & 291 & 4 & $41-43(42.1 \pm 0.9 \mathrm{~cm})$ \\
\hline 2 & 277 & 3 & $41-47(44.5 \pm 3.1 \mathrm{~cm})$ \\
\hline 3 & 253 & 3 & 47 \\
\hline 4 & 240 & 4 & $43-49(46.6 \pm 2.6 \mathrm{~cm})$ \\
\hline
\end{tabular}

Table 1. Codes, total length $\left(L_{\mathrm{T}} ; \mathrm{cm}\right)$ range and mean ( \pm standard deviation) of the 4 pregnant females of Sphyrna lewini and their near-term embryos $(n=14)$ captured off Puerto Madero in April 2016.

\begin{tabular}{|l|l|l|l|}
\hline Sampling site & Date of capture & $\boldsymbol{n}$ & $\boldsymbol{L}_{\mathbf{T}}$ \\
\hline La Reforma & Sept 2016 & 5 & $55-63 .(59.4 \pm 3.4 \mathrm{~cm})$ \\
\hline Teacapán & Aug 2016 & 5 & $52.8-56.8(54.2 \pm 1.7 \mathrm{~cm})$ \\
\hline Salina Cruz & Oct 2016 & 5 & $49.2-59.6(55.3 \pm 4.5 \mathrm{~cm})$ \\
\hline
\end{tabular}

Table 2. Sampling details, total length $\left(L_{\mathrm{T}} ; \mathrm{cm}\right)$ range and mean $( \pm$ standard deviation $)$ of the 15 young-of-theyear specimens of Sphyrna lewini collected in 2016 in three coastal nurseries of the Mexican Pacific.

\begin{tabular}{|l|l|l|}
\hline Hypothesis & Vertebrae & Ablation samples \\
\hline $\begin{array}{l}\text { 1. Elemental signatures in vertebrae of embryos from a } \\
\text { same litter are similar }\end{array}$ & EMBRYOS & SPOTS (Focus and Edge) \\
\hline $\begin{array}{l}\text { 2. Elemental profiles in vertebrae of embryos from a same } \\
\text { litter are similar }\end{array}$ & EMBRYOS & TRANSECTS (Focus - Edge) \\
\hline $\begin{array}{l}\text { 3. Elemental signatures in vertebrae of a mother match } \\
\text { with those of her embryos }\end{array}$ & EMBRYOS vs MOTHERS & SPOTS (Edge) \\
\hline $\begin{array}{l}\text { 4. In utero elemental profiles in the offspring's vertebrae } \\
\text { reflect migration patterns of pregnant females }\end{array}$ & YOY & TRANSECTS (Focus - Birthmark) \\
\hline
\end{tabular}

Table 3. Summary of the methodology employed to address the different hypotheses of this study. See Fig. 2 for the target areas of the vertebral sections (i.e focus, birthmark or edge) from the embryo, pregnant female and young-of-the-year ('YOY') specimens.

Vertebrae preparation for LA-ICP-MS analyses. Vertebrae were defrosted and the neural arch and extraneous tissue were removed. Individual centra were exposed, thoroughly rinsed, air dried, mounted on wooden holders with polyester resin and later cut into $0.4 \mathrm{~mm}$ thick sagittal sections with a Buehler low-speed Isomet saw. Vertebral sections were hand-polished with a series of progressively finer grades of lapping paper $(220,800$, and $3 \mu \mathrm{m}$ grit), ultrasonically cleaned for 5 minutes in Milli-Q water to remove surface contaminants, triple rinsed, dried for 24 hours and randomly affixed with double-sided tape to acid-washed petrographic slides (subsequently referred to as 'master slides'). One vertebra section from each specimen was used for analyses as it was shown that elemental signatures of $S$. lewini did not differ in individual sharks ${ }^{23,38}$. All cleaning and drying procedures were performed under a Class-100 laminar flow clean hood using trace-metal grade reagents, non-metallic instruments and $\mathrm{HNO}_{3}$ acid-washed glass slides to minimize contamination.

LA-ICP-MS analyses. The elemental composition of the vertebrae of S. lewini was quantified using a Photon-Machines Analyte 193 excimer UV laser ablation system (LA), connected to an Agilent Technologies 7500CX quadrupole inductively coupled plasma-mass spectrometer (ICP-MS). Raw data of the ion counts per second (cps) were collected for the following 21 elements: ${ }^{7} \mathrm{Li},{ }^{24} \mathrm{Mg},{ }^{43} \mathrm{Ca},{ }^{45} \mathrm{Sc},{ }^{51} \mathrm{~V},{ }^{53} \mathrm{Cr},{ }^{55} \mathrm{Mn},{ }^{57} \mathrm{Fe},{ }^{59} \mathrm{Co},{ }^{63} \mathrm{Cu}$, ${ }^{72} \mathrm{Ge},{ }^{85} \mathrm{Rb},{ }^{88} \mathrm{Sr},{ }^{89} \mathrm{Y},{ }^{114} \mathrm{Cd},{ }^{118} \mathrm{Sn},{ }^{137} \mathrm{Ba},{ }^{197} \mathrm{Au},{ }^{208} \mathrm{~Pb},{ }^{232} \mathrm{Th}$ and ${ }^{238} \mathrm{U}$ with ${ }^{43} \mathrm{Ca}$ being quantified for use as internal standard. These were screened in the vertebrae of S. lewini because this combination of masses minimizes potential interferences that can arise from isobaric spectral overlap, sample matrix effects, and the presence of molecular ions $s^{39}$ and was successfully used in previous studies for inferring the life history of sharks ${ }^{19,20,23-27}$. Even though it is the ${ }^{138} \mathrm{Ba}$ isotope that is usually assayed in studies of calcified structures, ${ }^{137} \mathrm{Ba}$ was screened in the vertebrae of S. lewini in this study for the sake of comparison with results reported in analogous study ${ }^{19}$. As the less abundant isotope $\left(11.2 \%{ }^{40}\right),{ }^{137} \mathrm{Ba}$ is slightly more challenging to assay reliably than its counterpart, ${ }^{138} \mathrm{Ba}\left(71.7 \%{ }^{40}\right)$, however this was not considered as a detrimental flaw to the present study because the use of a less abundant isotope would only increase the magnitude of change of the Sr:Ba ratio, though not the general pattern.

The consistency in vertebral microchemistry among embryos within each pregnant female's litter was tested before determining whether the elemental signatures deposited in the vertebrae of embryos reflected maternal vertebral microchemistry (Hypothesis 1; Table 3). Spots targeting the vertebral focus and edge of each embryo were ablated in order to quantify the elemental signatures deposited at the beginning of the gestation and at the time immediately prior to capture, respectively, and test this hypothesis (Fig. 2).

The temporal consistency in elemental profiles among embryos within each pregnant female's litter was also examined to verify that results obtained separately for the focus and the edge in the vertebrae of embryos were consistent for the time period between the beginning of the gestation and the time immediately prior to capture 


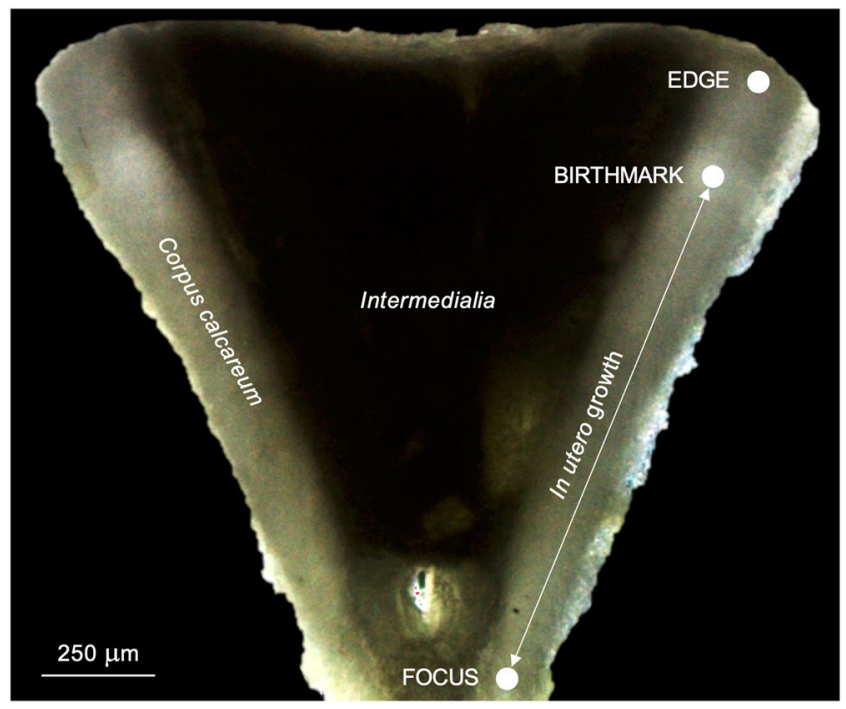

Figure 2. Sagittal section of a vertebra centrum from a young-of-the-year specimen of Sphyrna lewini, illustrating the terminology used for LA-ICP-MS analyses.

(i.e. in utero embryonic development) (Hypothesis 2; Table 3). Transects encompassing the area from the focus to the edge in the vertebrae from each embryo were ablated to characterize the individual elemental profiles and test this hypothesis (Fig. 2).

The hypothesis that vertebral microchemistry of embryos reflected that of pregnant females during the gestation period was tested by comparing the elemental signatures deposited at the vertebral edge of each pregnant female with her respective embryos (Fig. 2), as this region of the vertebrae provided a known spatial and temporal reference (i.e. time immediately prior to capture) that made the comparisons possible (Hypothesis 3; Table 3). Spots targeting the vertebral edge of each pregnant female were ablated so the resulting elemental signatures could be compared with the elemental signatures of vertebral edge previously quantified in their embryos.

Ultimately, the potential to infer the gestation-related movements of pregnant females using the in utero vertebral microchemistry of their offspring as a proxy was evaluated by measuring changes in ${ }^{88} \mathrm{Sr},{ }^{137} \mathrm{Ba}$ and ${ }^{208} \mathrm{~Pb}$ along transects encompassing complete in utero embryonic development from the focus to the birthmark (Fig. 2) of the young-of-the-year vertebrae (Hypothesis 4; Table 3). Strontium $\left({ }^{88} \mathrm{Sr}\right)$ and barium $\left({ }^{137} \mathrm{Ba}\right)$ were used as salinity change indicators of the pregnant female environmental histories because: (1) adult females of $S$. lewini primarily inhabit fully marine offshore habitats ${ }^{8-10}$ and (2), nursery areas of the species (i.e. estuaries and coastal bays $\mathrm{s}^{2,4,14,41-43}$ ) are typically characterized by significant freshwater inputs during the birthing season (i.e. May-August ${ }^{2,3,11}$ ) in the Mexican Pacific ${ }^{44}$, which was expected to influence the nearshore-offshore gradient of salinity and hence the $\mathrm{Sr}$ and Ba values ${ }^{29,45,46}$ during this period. The in utero variations of lead $\left({ }^{208} \mathrm{~Pb}\right)$ in the vertebrae were assessed as an alternate indicator of contaminated habitat use to aid in interpreting the observations based on ${ }^{88} \mathrm{Sr}$ and ${ }^{137} \mathrm{Ba}$.

Spots were ablated with $n=3$ replicates; circular spot size was $83 \mu \mathrm{m}$ with a laser repetition rate of $5 \mathrm{~Hz}$ and a $60 \mathrm{~s}$ duration. Transects were pre-ablated to remove possible external contamination. Pre-ablation scan speed was $108 \mu \mathrm{m} . \mathrm{s}^{-1}$, with a repetition rate of $2 \mathrm{~Hz}$ and a $108 \mu \mathrm{m}$ spot size. For data acquisition, ablation scan speed was 10 $\mu \mathrm{m} . \mathrm{s}^{-1}$, with a repetition rate of $10 \mathrm{~Hz}$ and an $83 \mu \mathrm{m}$ spot size. All ablation samples were entirely positioned within and along the corpus calcareum of the vertebral sections (Fig. 2).

Elemental data were acquired using an ICP-MS which employed Agilent Technologies ChemStation software operating in time-resolved analysis mode to collect raw data (cps) for the 21 target elements. NIST-612 silicate glass served as external calibration reference material ${ }^{47}$ and was ablated with two replicates before and after every fifth vertebral section was sampled. MACS-3 microanalytical carbonate standard material ${ }^{48}$ was ablated in brackets before and after each master slide to estimate experiment-wide levels of precision. Background data corresponding to gas blanks were collected for $60 \mathrm{~s}$ before and after each spot or transect scan was performed. Prior to data acquisition, the ICP-MS instrument was fine-tuned while ablating NIST-612 using $108 \mu \mathrm{m}$ wide transect scans running at $5 \mathrm{~Hz}$ and $86 \%$ power in order to maximize element counts and minimize noise. All laboratory facilities and instrumentation used for elemental analyses were located on the campus of the College of Marine Science, University of South Florida, St. Petersburg, FL, USA.

Data analyses. Elemental signatures in vertebrae: embryos versus pregnant females. Raw spot data (cps) were visually assessed within the software, and those portions of the signals displaying peaks likely associated with surface contaminants or other forms of instabilities were excluded from further processing. The following operations were then applied to the data associated with each spot sample: (1) background levels were removed by subtraction; (2) mass-specific spikes detected by the Grubbs test $(\alpha=0.05)$ were replaced with mean values; and (3) mass-specific drift in the sensitivity of the ICP-MS detector was corrected via linear interpolation. Raw spot data (cps) were then converted to single, mean (i.e. averaged across replicates) elemental concentration values (ppm) using NIST-612 data for external calibration and standardized to the ${ }^{43} \mathrm{Ca}$ data obtained simultaneously in 
the structure by deriving element:Ca ratios $\left(\mu \mathrm{mole} \cdot \mathrm{mole}^{-1}\right)$ to adjust for variability in instrument sensitivity and the amount of ablated material. Limits of detection (LOD) were estimated for samples based on 3.SD of the ion count rates (cps) of the corresponding gas blanks and converted to concentrations (ppm). Elements with $\geq 10 \%$ of the measures of concentration below LOD were omitted from subsequent analyses. Outliers among replicate spot scans were identified using a multivariate measure of outlyingness ${ }^{49}$ based on elemental concentrations ( $\left.\mathrm{ppm}\right)$. Replicates with outlyingness values $>10$ were excluded before reducing the data to mean ppm concentration value for each sample. Raw transect data (cps) were made compatible for direct comparisons by interpolating cell array of each vertebral transect so they all had the same number of data points as the longest one and generating mean integrated transect data of the retained elements (i.e. consistently recorded above LOD).

The null hypotheses that (1) no difference existed in the elemental signatures deposited at the vertebral focus and edge of embryos within each pregnant female's litter, (2) no difference existed among the elemental profiles of embryos within each litter, and that (3) no difference in the elemental signatures of edge existed between a pregnant female and her embryos were tested using permutational analysis of variance $\left(\right.$ PERMANOVA $\left.^{50}\right)$. Canonical analyses of principal coordinates $\left(\mathrm{CAP}^{51}\right)$ were subsequently employed to visualize the within-group similarities detected using PERMANOVA and test the ability of the models to accurately distinguish among pregnant females and their corresponding embryos based on vertebral microchemistry. Leave-one-out cross-validation (LOO-CV) was used to assess the overall classification accuracy of each CAP model and build a confusion matrix summarizing the occurrence of group-specific misclassifications. Proportional chance criterion (PCC) was used to test the significance of the observed overall classification success rates of the CAP models compared with that expected by chance ${ }^{52}$.

Spot (i.e. focus and edge) and transect data were analyzed as multi-elemental signatures of the mean (i.e. averaged across replicates) element:Ca ratios and mean integrated transect data of the retained elements, respectively. A Euclidean distance-based dissimilarity matrix constructed from the mean element:Ca ratios or elemental profiles served as multiple, quantitative explanatory variables in PERMANOVA and CAP design, with individual pregnant females and/or litters serving as the categorical response variables.

Inferring the gestation-related movements of pregnant females. Transect data for ${ }^{88} \mathrm{Sr},{ }^{137} \mathrm{Ba}$ and ${ }^{208} \mathrm{~Pb}$ (used as $\mathrm{Sr}: \mathrm{Ba}$ and $\mathrm{Pb}: \mathrm{Ca}$ raw cps ratios) were plotted versus vertebral transect distance from the focus ( $\mu \mathrm{m})$ of each young-of-the-year to evaluate the viability to employ the in utero elemental profiles of S. lewini to infer the gestation-related movements of pregnant females. Data were used as raw cps for the sake of comparison with analogous study involving S. lewini in the Mexican Pacific ${ }^{7}$. An 11-point running average window size was used to filter/smooth the data, reduce the noise, and aid in identifying the underlying pattern of the $\mathrm{Sr}: \mathrm{Ba}$ and $\mathrm{Pb}: \mathrm{Ca}$ profiles $^{53}$. The same procedure was subsequently applied to the embryo transect data to compare the patterns observed in their elemental profiles with those generated from the young-of-the-year while in utero. Evidences of pregnant females possibly entering estuarine or nearshore habitats for parturition were expected to be shown by a sharp decline of the Sr:Ba ratio (between 150 and $400^{7}$ ) in the in utero profiles prior to birth combined with an increase of the $\mathrm{Pb}: \mathrm{Ca}$ ratio at the same time ${ }^{7}$. Although previous study recently confirmed that $\mathrm{Sr}: \mathrm{Ca}$ and $\mathrm{Ba}: \mathrm{Ca}$ were inversely related relative to each other in the vertebrae of $S$. lewini relative to the nearshore-offshore environmental gradient in the region of study ${ }^{7}$, this assumption was also verified in the present study before inferences on the movements of pregnant females could be made based on their offsprings' in utero Sr:Ba profiles.

When a marked shift was observed in the in utero profiles of a sample, the total length of the individual at that time $t$ of the embryonic development was estimated using the back-calculation Fraser-Lee method ${ }^{54}(1)$ :

$$
L_{t}=\left[\left(R_{t}\right)\left(R_{V}\right)^{-1}\right]\left(L_{C}-\mathrm{a}\right)+\mathrm{a}
$$

where $L_{\mathrm{t}}$ is the back-calculated total length corresponding to age $t$ (i.e. time of the pregnant female habitat shift), $R_{\mathrm{t}}$ corresponds to the vertebral transect distance from the focus to the elemental shift identified in utero at age $t, R_{V}$ is the vertebrae centrum radius, $L_{C}$ the total length at the time of capture of the individual (i.e. young-of-the-year or embryo) and $a$ is intercept of an established linear relationship between $R_{\mathrm{V}}$ and $L_{\mathrm{C}}{ }^{54}$, which is $L_{\mathrm{C}}=17.349$ $R_{V}+14.516$ for juvenile specimens of S. lewini in the Mexican Pacific ${ }^{55}$.

The Fraser-Lee equation was selected as a back-calculation method in order to correct for bias induced when the $R_{\mathrm{V}}-L_{\mathrm{C}}$ linear regression does not pass through the origin (such as is the case for S. lewini) by using the intercept $a$ estimated from the $R_{\mathrm{V}}-L_{\mathrm{C}}$ relationship as a correcting factor in Eq. (1) ${ }^{56}$. Estimating the in utero back-calculated length at the time of the pregnant female habitat shift was considered necessary in this study to emphasize the importance of protecting these individuals when entering nearshore habitats a few $\mathrm{cm}$ before the embryos have reached a full-term total length. Although back-calculation may not adequately describe faster embryonic growth during the early stages of the gestation ${ }^{57}$, this was not considered as an issue in the present study because the in utero total lengths of the individuals at the time of the pregnant female habitat shift were estimated for the period corresponding to the late stages of the gestation and the parameters used in Eq. (1) were derived from juveniles, which allowed to avoid bias induced by mature individuals exhibiting different growth rates ${ }^{58}$.

All elemental data processing and multivariate statistical analyses were performed using the free download Fathom Toolbox for Matlab ${ }^{\text {TM59 }}$. For more details on the data processing and multivariate statistical analyses, please refer to the readme files and corresponding Matlab codes available on GitHub.

Compliance with ethical standards. All sample collection was carried out in accordance with relevant national guidelines and regulations for the care and use of animals. The samples used for this study were obtained from dead specimens of scalloped hammerhead sharks destined for human consumption, which were legally caught by fishers in possession of the proper fishing permits issued by the National Commission for Aquaculture and Fisheries from the Mexican Ministry of Agriculture and Rural Development (CONAPESCA: https://www. 
(a)

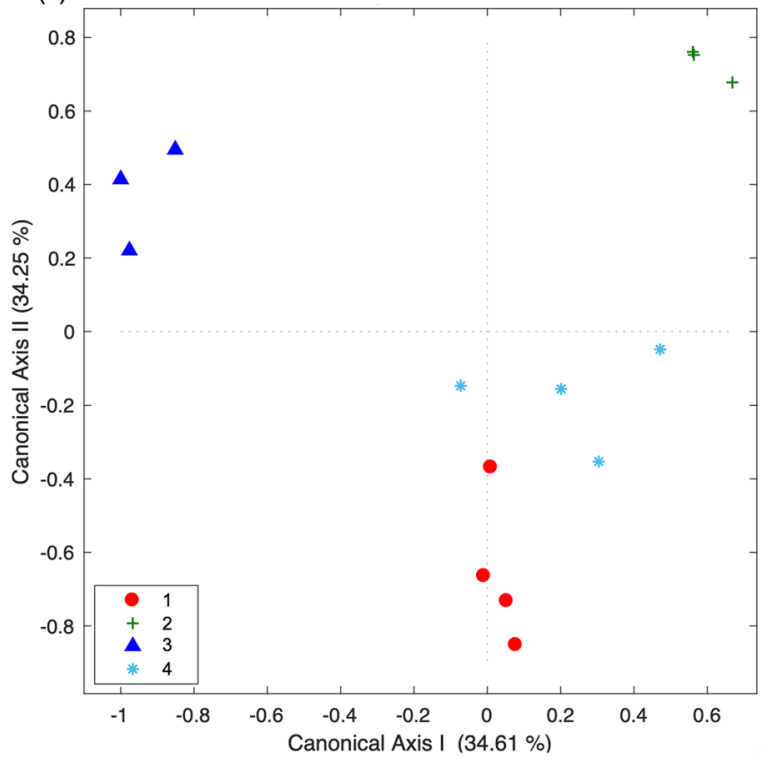

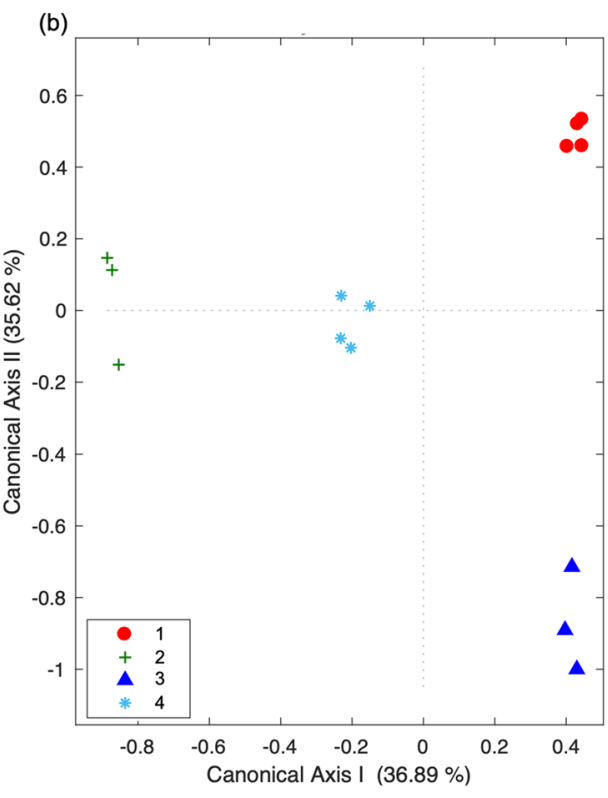

Figure 3. Canonical analyses of principal coordinates ordination diagrams illustrating the spatial variation of (A) multi-elemental signatures deposited at the vertebral focus $\left(\mathrm{CAP}_{\mathrm{FOCuS}}\right)$ and (B) multi-elemental profiles $\left(\mathrm{CAP}_{\text {TRANSECT }}\right)$ quantified in the embryos of Sphyrna lewini $(n=14)$. Numbers refer to the female's litter codes (see Table 1).

gob.mx/conapesca), and in agreement with the Mexican Official Regulation NOM-029-PESC-2006 regarding the sustainable exploitation of sharks and rays (NORMA Oficial Mexicana NOM-029-PESC-2006, Pesca responsable de tiburones y rayas. Especificaciones para su aprovechamiento, https://www.gob.mx/cms/uploads/attachment/ file/135366/49.-_NORMA_OFICIAL_MEXICANA_NOM-029-PESC-2006.pdf).

\section{Results}

Elemental signatures in vertebrae: embryos versus pregnant females. The vertebrae from 4 pregnant females of $S$. lewini captured off Puerto Madero and 3 to 4 embryos from their respective litters were available for this study (Hypotheses 1-3; Table 3). Pregnant females ranged from 240 to $291 \mathrm{~cm}$ of $L_{\mathrm{T}}$ (mean $\pm \mathrm{SD}=265 \pm 23 \mathrm{~cm} L_{\mathrm{T}}$; Table 1 ). Embryos ranged from 41 to $49 \mathrm{~cm}$ of $L_{\mathrm{T}}\left(n=14 ; 44.8 \pm 2.8 \mathrm{~cm} L_{\mathrm{T}}\right.$; Table 1$)$. Based on the reported length-at-birth of S. lewini in the Mexican Pacific (i.e. $41-53 \mathrm{~cm} L_{\mathrm{T}}{ }^{2-4,11}$ ), these embryos were about to be born.

The mean percentage of the elemental concentration data below the limits of detection (LOD) was $\leq 10 \%$ for all elements (i.e. $\left.{ }^{7} \mathrm{Li},{ }^{24} \mathrm{Mg},{ }^{55} \mathrm{Mn},{ }^{57} \mathrm{Fe},{ }^{59} \mathrm{Co},{ }^{85} \mathrm{Rb},{ }^{88} \mathrm{Sr},{ }^{89} \mathrm{Y},{ }^{114} \mathrm{Cd},{ }^{118} \mathrm{Sn},{ }^{137} \mathrm{Ba},{ }^{208} \mathrm{~Pb}\right)$, except for ${ }^{45} \mathrm{Sc}(42.9 \%),{ }^{51} \mathrm{~V}$ (57.1\%), ${ }^{53} \mathrm{Cr}(64.3 \%),{ }^{72} \mathrm{Ge}(71.4 \%),{ }^{89} \mathrm{Y}(64.3 \%),{ }^{114} \mathrm{Cd}(57.1 \%),{ }^{197} \mathrm{Au}(71.4 \%),{ }^{232} \mathrm{Th}(63.3 \%)$ and ${ }^{238} \mathrm{U}(78.6 \%)$ which were not regularly detected in the vertebrae of embryos and pregnant females. For more details on the mean ( \pm standard deviation) element:Ca ratios $\left(\mu\right.$ mole $\left.\cdot m_{0} e^{-1}\right)$ quantified at the vertebral focus and edge of embryos and pregnant females, please refer to Table S1 from the Supplementary Information.

The multi-elemental signatures deposited at the vertebral focus of embryos were consistent within each pregnant female's litter (PERMANOVA: $0.68<P<1$; Hypothesis 1), $85.7 \%$ of the embryos were correctly assigned within each corresponding litter by the $\mathrm{CAP}_{\text {FOCUs }}$ model classifier $\left(\mathrm{CAP}_{\text {FOCUs: }}: m=8, G_{\text {prop }}=100 \%, \operatorname{Tr}_{\text {stat }}=2.66\right.$, $P=0.001$; Fig. $3 \mathrm{~A}$ ) and this was significantly better than the $25.5 \%$ accuracy rate expected by chance (PCC: $P=0.001)$.

The multi-elemental profiles were also consistent among embryos within each pregnant female's litter (PERMANOVA: $0.36<P<1$, Hypothesis 2); $60 \%$ of the embryos were correctly assigned within each corresponding litter by the $\mathrm{CAP}_{\text {TRANSECT }}$ model classifier $\left(\mathrm{CAP}_{\text {TRANSECT }}: m=11, G_{\text {prop }}=86.9 \%, \operatorname{Tr}_{\text {stat }}=2.7, P=0.04\right.$; Fig. $3 \mathrm{~B}$ ) and this was significantly better than the $40 \%$ accuracy rate expected by chance (PCC: $P=0.04$ ).

The multi-elemental signatures deposited at the vertebral edge were consistent between each pregnant female and her embryos (PERMANOVA: $P=1$; Hypothesis 3 ); $88.9 \%$ of the samples were correctly assigned within each corresponding group (combining embryos and pregnant females) by the $\mathrm{CAP}_{\mathrm{EDGE}}$ model classifier $\left(\mathrm{CAP}_{\mathrm{EDGE}}\right.$ : $m=12, G_{\text {prop }}=100 \%, \operatorname{Tr} c_{\text {stat }}=2.85, P=0.001$; Fig. 4$)$, which was significantly better than the $26.4 \%$ accuracy rate expected by chance (PCC: $P=0.001$ ). For details on the elements driving most of the differences among elemental signatures deposited at the vertebral focus and edge of embryos and pregnant females, please refer to Figs. S1 and S2 from the Supplementary Information.

Inferring the gestation-related movements of pregnant females. The vertebrae from 15 young-of-the-year specimens of $S$. lewini ranging from 49.2 to $59.6 \mathrm{~cm}$ of $L_{\mathrm{T}}$ (mean $\pm \mathrm{SD}=55.7 \pm 4.1 \mathrm{~cm} L_{\mathrm{T}}$; Table 2) were available for this study. Elemental profiles quantified in their vertebrae were compared with those previously quantified in the vertebrae of the 14 near-term embryos (Table 1). 


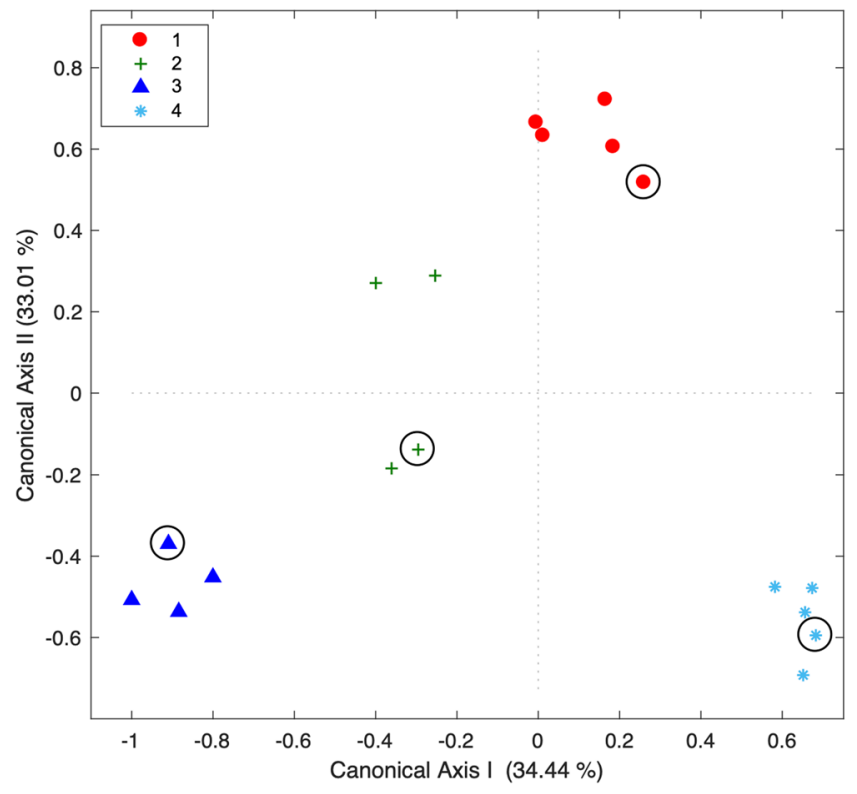

Figure 4. Canonical analysis of principal coordinates $\left(\mathrm{CAP}_{\mathrm{EDGE}}\right)$ ordination diagram illustrating the spatial variation of elemental signatures deposited at the vertebral edge of the pregnant females of Sphyrna lewini $(n=4)$ and their embryos $(n=14)$. Numbers refer to the female's litter codes (see Table 1$)$. Symbols with black circles correspond to the litter's female.

All individuals (i.e. embryos and young-of-the-year) exhibited the same pattern of variation in their in utero $\mathrm{Sr}: \mathrm{Ca}$ and Ba:Ca profiles. The Sr:Ca ratio progressively increased throughout gestation and eventually slightly declined prior to parturition whereas the Ba:Ca ratio drastically declined at the beginning of the gestation (i.e. focus), remained particularly low and constant during its intermediate stage and then increased prior to birth (i.e. vertebral edge or birthmark; see example in Fig. 5). Although $\mathrm{Sr}: \mathrm{Ca}$ and Ba:Ca were effectively inversely related relative to each other, $\mathrm{Sr}: \mathrm{Ba}$ alone provided a better tool for examining the individual environmental histories rather than the joint comparison of the $\mathrm{Sr}: \mathrm{Ca}$ and $\mathrm{Ba}: \mathrm{Ca}$ ratios because it allowed to combine and highlight the differences observed for both (Fig. 5). Regarding variations of $\mathrm{Pb}$ along the in utero profiles, all samples exhibited a sharp increase of the $\mathrm{Pb}: \mathrm{Ca}$ ratio prior to birth when compared to earlier in the gestation (Fig. 5). Accordingly, $\mathrm{Sr}: \mathrm{Ba}$ was used as primary environmental indicator combined with $\mathrm{Pb}: \mathrm{Ca}$ in order to support the observations based on Sr and Ba.

Embryos and young-of-the-year of S. lewini displayed large variations in Sr:Ba while in utero, with overall values that could vary from $<100$ to 1200 within individuals, suggesting that pregnant females remained in environments of contrasting salinities throughout gestation (Fig. 5). The Sr:Ba ratio also differed widely among individuals, with the maximum individual values ranging between 300 and 1200 and the samples from Salina Cruz displaying the highest (1050-1200). Overall, all embryos and young-of-the-year exhibited relatively low $\mathrm{Sr}$ :Ba values at the vertebral focus (0-200) while the Sr:Ba values quantified at the vertebral birthmark of the young-of-the-year were more variable (100-600) among individuals (Figs. 5 and 6).

A single pattern was found in the in utero Sr:Ba profiles of embryos (subsequently referred to as 'Pattern 1'); Sr:Ba gradually increased until the highest individual value was reached (between 600 and 1300) and then rapidly declined to values between 300 and $<100$ shortly prior to the female capture, which corresponded to a sharp increase of the $\mathrm{Pb}: \mathrm{Ca}$ ratio at the same time (Fig. 5). Back-calculated length of embryos at the time of the decline in $\mathrm{Sr}$ :Ba ranged between $37.6 \mathrm{~cm}$ and $45.9 \mathrm{~cm}$ of $L_{\mathrm{T}}\left(41.1 \pm 2.1 \mathrm{~cm} L_{\mathrm{T}}\right)$, which corresponded to a difference of size of approximately $4.2 \pm 1.9 \mathrm{~cm}$ of $L_{\mathrm{T}}$ with that of the embryos at the pregnant female capture.

The same pattern of variation was observed in the in utero $\mathrm{Sr}$ :Ba profiles of most young-of-the-year $(n=11$; 73.3\%) (i.e. 'Pattern 1'; Fig. 6); Sr:Ba gradually increased until the highest individual value was reached (6001200 ), and then rapidly declined to values between 350 and $<100$ shortly prior to birth, which also corresponded to an increase of the $\mathrm{Pb}$ :Ca ratio at the same time (Fig. 6). The in utero back-calculated length at the time of the Sr:Ba decline ranged between 36.3 and $52.3 \mathrm{~cm}$ of $L_{\mathrm{T}}\left(43.9 \pm 5.4 \mathrm{~cm} L_{\mathrm{T}}\right)$ for these samples, which was not significantly different from that estimated for the embryos (i.e. $41.1 \pm 2.1 \mathrm{~cm}$; ANOVA: $F=2.57, P>0.05$ ). The remaining young-of-the-year specimens $(n=4 ; 26.6 \%)$ exhibited low but relatively constant values of the Sr:Ba ratio $(0-200)$ while in utero (subsequently referred to as 'Pattern 2'; Fig. 6), suggesting that these specimens' mothers possibly remained nearshore throughout gestation. These specimens were also found to exhibit significantly higher values of the $\mathrm{Pb}: \mathrm{Ca}$ ratio at the beginning of the gestation when compared to later in the embryonic development (i.e. focus; $1.25 \times 10^{-6} \pm 1.03 \times 10^{-6}$ versus $0.46 \times 10^{-6} \pm 0.77 \times 10^{-6}$ in specimens exhibiting 'Pattern $1^{\text {'; }}$ Mann-Whitney test: $P<0.001$ ), after which the ratio remained relatively constant (Fig. 6). 

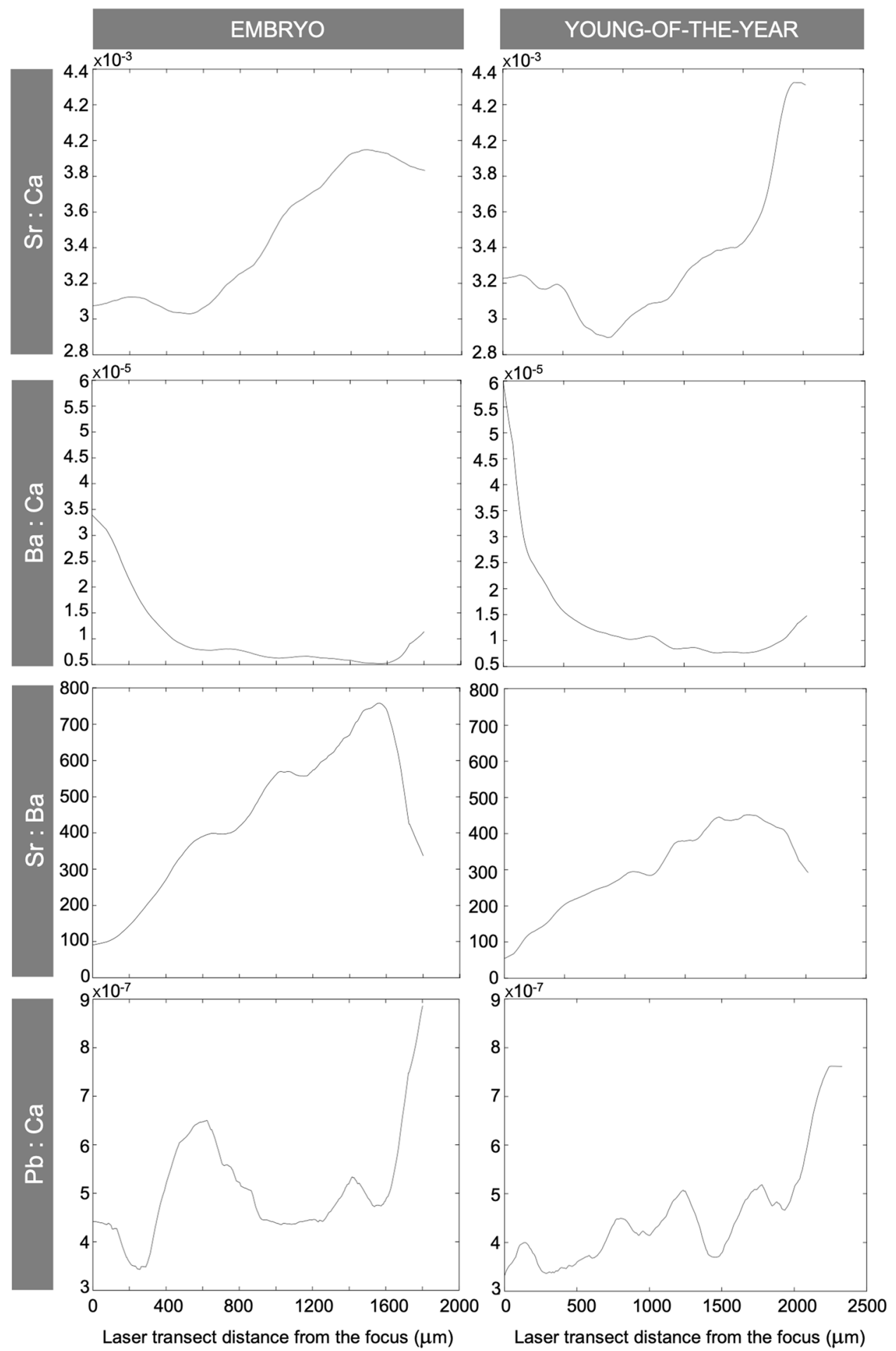

Figure 5. Individual in utero profiles of the $\mathrm{Sr}: \mathrm{Ca}, \mathrm{Ba}: \mathrm{Ca}, \mathrm{Sr}: \mathrm{Ba}$ and $\mathrm{Pb}: \mathrm{Ca}$ ratios quantified in the vertebrae of an embryo (left) and a young-of-the-year (right) specimen of Sphyrna lewini.

\section{Discussion}

Elemental signatures in vertebrae: embryos versus pregnant females. Vertebral microchemistry of pregnant females of $S$. lewini and some of their near-term embryos was analyzed in this study to address important questions concerning the gestation-related migratory patterns of the species in the Mexican Pacific. Previous studies recently demonstrated that elemental signatures in the vertebrae of S. lewini can serve as broad-scale effective spatial markers in the Mexican Pacific whether individuals have occupied coastal or oceanic environments and irrespective of the ontogenetic stage ${ }^{7,23}$, and the results of this study indicated that elemental signatures of the species can also serve as maternal tags, when these are quantified in the area of the vertebrae that was deposited 

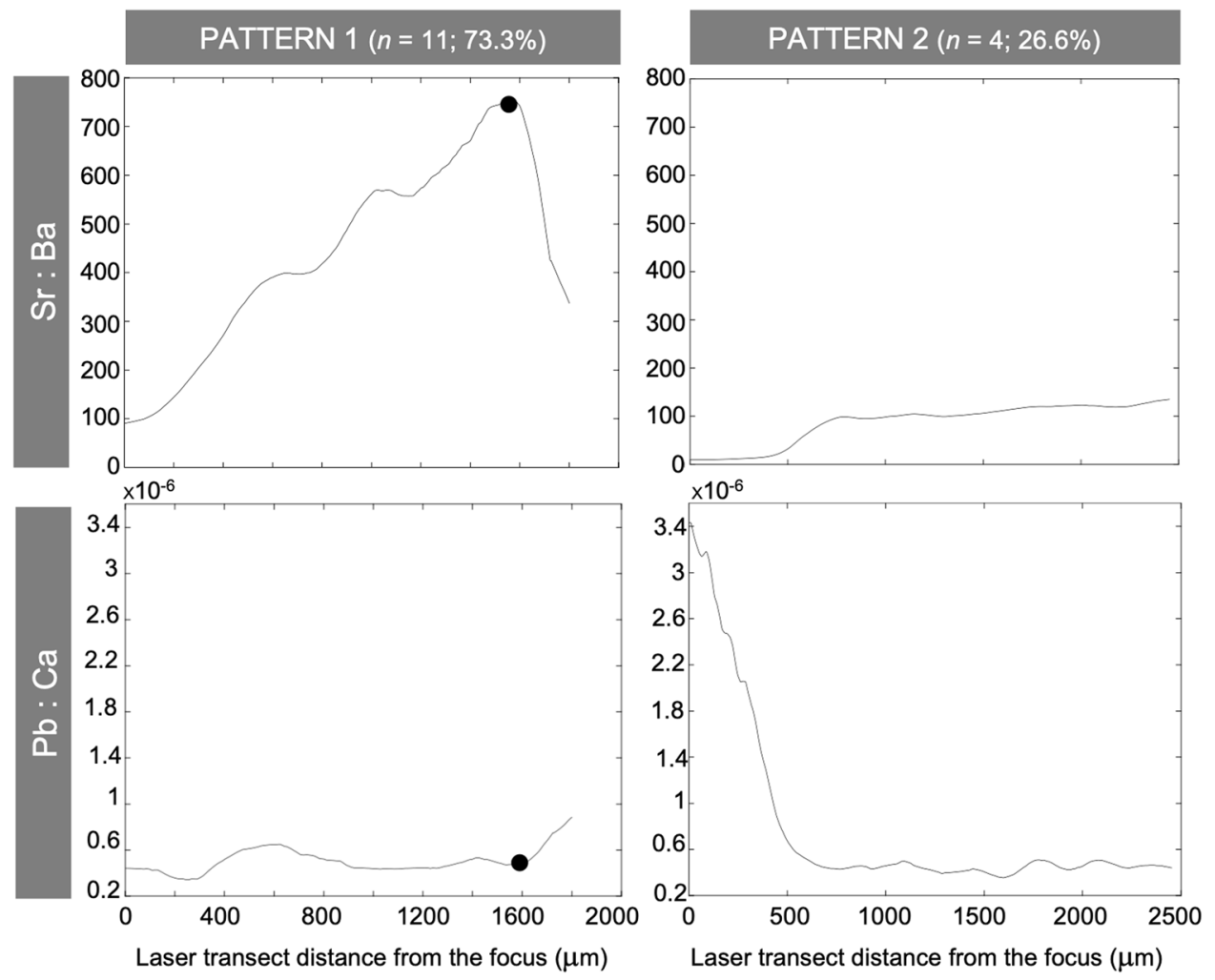

Figure 6. Examples of the in utero $\mathrm{Sr}: \mathrm{Ba}$ and $\mathrm{Pb}: \mathrm{Ca}$ ratio profiles quantified in the vertebrae from two youngof-the-year specimens of Sphyrna lewini, illustrating the two patterns identified (i.e. 'Pattern 1' and 'Pattern 2'). Dots indicate possible habitat shift of pregnant females towards nearshore habitats.

during the in utero embryonic development. Although only few samples could be collected, vertebral microchemistry of S. lewini allowed to successfully distinguish among embryos from the distinct litters (60-88.9\%), whether based on discrete elemental signatures deposited at the vertebral focus and edge (Hypothesis 1; Table 3) or elemental profiles that encompassed complete in utero development (Hypothesis 2; Table 3), demonstrating the temporal consistency in the elemental deposition among embryos of the species within a same litter.

Vertebral microchemistry of embryos was also found to reflect that of pregnant females during the gestation (Hypothesis 3; Table 3), at least at the edge (i.e. region of the vertebrae deposited immediately prior to capture), as this region of the vertebrae provided the only known spatial and temporal reference from which the comparisons could be made. Considering to compare elemental signatures deposited at another time such as the beginning of the gestation (i.e. focus) was not possible because there is no temporal reference in the vertebrae of pregnant females allowing to calibrate the period of the gestation in terms of months (i.e. $10-11$ months ${ }^{11,12}$ ). Nevertheless, the fact that elemental signatures were temporally consistent among embryos within each litter and that vertebral microchemistry allowed to successfully classified (88.9\%) pregnant females with their respective embryos based on their unique elemental signatures of vertebral edge indicated that in utero vertebral microchemistry of $S$. lewini can serve as maternal tag from a few weeks after fertilization, when the formation of a placenta allows the embryos to be directly nourished from the mother's blood stream, to the end of the gestation.

It was recently stated that pregnant female's transfer of substantial amounts of organic contaminants (i.e. polychlorinated biphenyls and chlorinated pesticides) to their embryos through the process of fetal nutrition ${ }^{60}$ might potentially alter the maternal site-specific markers deposited in the vertebrae of embryos while in utero ${ }^{23}$. Although it is unknown whether maternal contaminant offloading can effectively alter the vertebral microchemistry of embryos of S. lewini, the lipophilic nature of organochlorines does not support this assumption as such contaminants primarily accumulate within the hepatic tissue ${ }^{61,62}$. Furthermore, the fact that in this study vertebral microchemistry of pregnant females was not significantly different from that of their embryos indicated that elemental signatures in vertebrae of embryos are likely not altered through the mechanisms of contaminant transfer, thus confirming that in utero elemental signatures of S. lewini can serve as intrinsic markers of the environmental histories of pregnant females during the gestation.

Inferring the gestation-related movements of pregnant females. Conventional tagging studies indicated that adult females of $S$. lewini typically aggregate offshore and later return to coastal habitats for parturition $^{8-10}$. Although the patterns of migration and habitat use of pregnant individuals have remained unknown despite extensive study, yet it could be assumed that the female reliance on coastal habitats for parturition combined with an annual reproductive cycle ${ }^{11,12}$ had restricted their dispersal to highly oceanic habitats during the gestation. The novel approach developed in this study allowed to elucidate some of these aspects through the 
analysis of the female offspring's in utero vertebral microchemistry, using $\mathrm{Sr}: \mathrm{Ba}$ and $\mathrm{Pb}: \mathrm{Ca}$ as indicators of environmental histories (Hypothesis 4; Table 3). Even though the lack of water chemistry data and telemetric data against which to compare the results of this study limits the power of such inferences, analyses of the in utero $\mathrm{Sr}: \mathrm{Ba}$ and $\mathrm{Pb}: \mathrm{Ca}$ profiles allowed to detect two apparently distinct migratory patterns of the pregnant females of S. lewini in terms of the movements between nearshore and more oceanic environments.

More specifically, the results indicated that most pregnant females (73.3\%) apparently progressively migrated offshore from the initial stages of the gestation (i.e. a few weeks after fertilization) before quickly heading back to the coastal nurseries prior to parturition ('Pattern 1'), when embryos had reached a size between approximately 41.1 and $43.9 \mathrm{~cm}$ of $L_{\mathrm{T}}$. Similarities in such habitat shift among pregnant females at this time of the gestation were shown by marked decline of the Sr:Ba ratio to values between 300 and $<100$ prior to birth in the in utero $\mathrm{Sr}$ :Ba profiles of young-of-the-year and embryos, in accordance with previously observed changes in the vertebral microchemistry of adult specimens of S. lewini when entering nearshore habitats $(150-400)^{7}$, assuming that variations in Sr and Ba effectively reflect the gradient of salinity changes of the environment ${ }^{17,29}$.

These observations were further informed by the analyses of the in utero $\mathrm{Pb}$ :Ca profiles that showed a sharp increase of the ratio prior to birth in both embryos and young-of-the-year, possibly indicative of pregnant females entering nearshore contaminated habitats for parturition, even though the assumption that incorporation of $\mathrm{Pb}$ in the vertebrae effectively reflects the exposure of a shark to contamination derived from anthropogenic sources has not been explicitly tested. Nevertheless, the fact that (1) embryos of pregnant females of S. lewini captured nearshore were found in this study to exhibit particularly higher $\mathrm{Pb}$ :Ca values at the vertebral edge when compared to earlier in the gestation, and that $(2)^{208} \mathrm{~Pb}$ in the vertebrae of $S$. lewini was found in previous study to be characteristic of the specimens captured in nearshore $\operatorname{areas}^{7}$ strongly influenced by anthropogenic sources of trace metal and pollutant inputs ${ }^{63-65}$ (when compared to individuals captured offshore ${ }^{7}$ ) indicated that $\mathrm{Pb}$ could be used as a complementary indicator of environmental history of S. lewini to support the conclusions based on $\mathrm{Sr}$ and $\mathrm{Ba}$.

Taking this into account, the results of this study also suggested that some pregnant females (23.3\%) apparently remained nearshore during complete gestation, as shown by low but constant values of the Sr:Ba ratio $(<200)$ along their offspring's in utero profiles, associated with relatively high but constant values of the $\mathrm{Pb}: \mathrm{Ca}$ ratio ('Pattern 2'). This possible behavior has not been documented before for S. lewini and the reasons why some females presumably remained nearshore during the gestation are unknown, especially considering that adult stages of S. lewini are thought to migrate offshore as a strategy to increase their foraging success by feeding on energy-rich pelagic preys ${ }^{5}$. Nevertheless, the fact that only a small proportion $(26.6 \%)$ of the individuals were found to exhibit this pattern precluded robust conclusion regarding this point, especially since sample size available for this study was in fact relatively low.

On the other hand, it might be stated that the among-individual differences observed in the Sr:Ba patterns and shifts might be driven by other factors than salinity such as variations in temperature, dietary preferences or individual-specific physiology (as shown for some teleosts ${ }^{66,67}$ ), and hence be not fully reflecting the movements of females across the nearshore-offshore gradient of salinity change. However, experimental evidences showed that: (1) Sr and Ba are not physiologically regulated and their incorporation in the vertebrae being primarily derived from branchial uptake, representative of the environmental concentrations, but not affected by somatic growth nor vertebral precipitation rate ${ }^{16,18}$ and (2), that temperature positively affected the incorporation of both $\mathrm{Sr}$ and $\mathrm{Ba}$ in the vertebrae of sharks ${ }^{18}$, and hence would not affect the overall $\mathrm{Sr}: \mathrm{Ba}$ ratio variations if females were to move into warmer (or cooler) waters during the gestation, regardless of the nearshore-offshore gradient of salinity. Caution should be however taken regarding the latter because conflicting evidences on the effect of temperature were found with round stingray Urobatis halleri, as temperature negatively affected the incorporation of $\mathrm{Ba}$, though not that of $\mathrm{Sr}$, in its vertebrae ${ }^{16}$. Nevertheless, analyses of the $\mathrm{Pb}: \mathrm{Ca}$ ratio were used in this study as a complementary indicator of environmental history to further evidence the movements of pregnant females into the nearshore habitats, and the results were consistent with the observations based on Sr:Ba.

It was recently suggested that in the Mexican Pacific females of $S$. lewini may probably give birth in variable environments and/or that the use of coastal nurseries may be less defined for this species than previously assumed $^{7}$, and the fact that in this study Sr:Ba values quantified at the young-of-the-year vertebral birthmark was found to differ widely among individuals $(<100-600)$ also supports this assumption. Behavioral plasticity towards nursery habitat selection for parturition might effectively be a strategy of the females to enhance their offspring survival by differing its vulnerability to predators and a potential lack of foraging success among regions ${ }^{7}$.

It is also important to note that even if the results of this study suggested that females remained nearshore at the beginning of the gestation because the $\mathrm{Sr}$ :Ba values quantified at the vertebral focus were found to be particularly low (50-200) in all individuals (while $\mathrm{Pb}$ :Ca was comparatively higher), conclusions regarding this point remain tentative because elemental data for this area of the vertebrae might primarily reflect vitellogenesis (i.e. yolk deposition) rather than the actual initial stage of the gestation, as placentation generally occurs within a few weeks after fertilization ${ }^{34}$. Yolk-based nourishing of embryos during the first weeks of gestation may possibly lead to a lag in the time required for the embryo vertebral microchemistry to reflect variations in the chemistry of the surrounding water to which the pregnant female was exposed during these weeks. Accordingly, the in utero elemental profiles of S. lewini may be informative on the migration patterns of pregnant females only once embryos were directly fed through the mother's blood stream, a few weeks after fertilization ${ }^{34}$.

Nevertheless, yet it appeared that pregnant females of $S$. lewini likely exhibited two distinct migratory patterns in the Mexican Pacific, as they either (1) progressively migrated offshore before quickly returning to coastal nurseries before term, or (2) possibly remained nearshore during complete embryonic development, supporting the assumption that overall females might exhibit relatively short dispersal to the oceanic habitats during the gestation. Alternating between two migratory patterns during the gestation may be a strategy of females to reduce their vulnerability to stressors or unfavorable environmental conditions among regions ${ }^{68-70}$ and optimize chances to complete a full-term gestation. 
Considering the life history and global endangered status of S. lewini ${ }^{71}$, current management measures in the Mexican Pacific such as the regulation norm of the commercial shark fishery (NOM-029-PESC-2006 ${ }^{72}$ ) and its seasonal prohibition between May and July (NOM-009-SAG/PESC-2015 ${ }^{73}$ ) may be insufficient for the sustainable management of the population. Pregnant females may be particularly susceptible to fisheries when remaining nearshore or entering coastal nurseries slightly before term, therefore limiting their possibilities to complete gestation to the term ${ }^{2}$ and reducing the reproductive potential of the population as it is briefly centralized in coastal areas ${ }^{23}$. Additional information on the movements of reproductive females provided by fine-scale telemetric studies is required to determine how such strategies of migration could potentially impact the reproductive potential of the population.

\section{Data availability}

The Matlab codes used to undertake the analyses performed in this study and prepare the figures and tables presented is freely available on GitHub (https://github.com/clairecoiraton/HammerheadInUteroMicrochemistry_ MatlabCode.git).

Received: 26 August 2019; Accepted: 20 January 2020;

Published online: 04 February 2020

\section{References}

1. Compagno, L. J. V. FAO species catalogue. Vol. 4. Part 2. Sharks of the world: an annotated and illustrated catalogue of shark species known to date. FAO Fisheries Synopsis. (1984).

2. Coiraton, C., Amezcua, F. \& Salgado-Ugarte, I. H. Estructura de longitudes de las capturas del tiburón martillo común (Sphyrna lewini) en el Pacífico mexicano. Cienc. Pesq. 25, 27-40 (2017).

3. Alejo-Plata, M. C., Gómez-Márquez, J. L., Ramos, S. \& Herrera, E. Presencia de neonatos y juveniles del tiburón martillo Sphyrna lewini (Griffith \& Smith, 1834) y del tiburón sedoso Carcharhinus falciformis (Müller \& Henle, 1839) en la costa de Oaxaca, Mexico. Rev. Biol. Mar. Oceanogr. 42, 403-413 (2007).

4. Anislado-Tolentino, V. Ecología pesquera del tiburón martillo Sphyrna lewini (Griffith y Smith, 1834) en el litoral del estado de Michoacán, México. (Universidad Nacional Autónoma de México, México, 2000).

5. Klimley, A. P. The determinants of sexual segregation in the scalloped hammerhead shark, Sphyrna lewini. Environ. Biol. Fishes 18, 27-40 (1987).

6. Hoyos-Padilla, E. M., Ketchum, J. T., Klimley, A. P. \& Galván-Magaña, F. Ontogenetic migration of a female scalloped hammerhead shark Sphyrna lewini in the Gulf of California. Anim. Biotelemetry 2, 17 (2014).

7. Coiraton, C., Amezcua, F. \& Ketchum, J. T. New insights into the migration patterns of the scalloped hammerhead shark Sphyrna lewini based on vertebral microchemistry. Mar. Biol. (in press).

8. Klimley, A. P. Schooling in Sphyrna lewini, a species with low risk of predation: a non-egalitarian state. Z. Tierpsychol. 70, 297-319 (1985).

9. Klimley, A. P. Social organization of schools of the scalloped hammerhead shark, Sphyrna lewini (Griffith and Smith), in the Gulf of California. Scripps Institution of Oceanography, https://doi.org/10.1126/science.84.2169.83 (University of California, San Diego, 1983).

10. Klimley, A. P. \& Nelson, D. R. Diel movement patterns of the scalloped hammerhead shark (Sphyrna lewini) in relation to El Bajo Espiritu Santo: a refuging central-position social system. Behav. Ecol. Sociobiol. 15, 45-54 (1984).

11. Torres-Huerta, A. M., Villavicencio-Garayzar, C. \& Corro-Espinosa, D. Reproductive biology of the scalloped hammerhead shark Sphyrna lewini Griffith \& Smith (Sphyrnidae) in the Gulf of California. Hidrobiologica 18, 227-237 (2008).

12. Bejarano-Álvarez, M., Galván-Magaña, F. \& Ochoa-Baez, R. I. Reproductive biology of the scalloped hammerhead shark Sphyrna lewini (Chondrichthyes: Sphyrnidae) off south-west Mexico. aqua Int. J. Ichthyol. 17, 11-22 (2011).

13. Harry, A. V., Macbeth, W. G., Gutteridge, A. N. \& Simpfendorfer, C. A. The life histories of endangered hammerhead sharks (Carcharhiniformes, Sphyrnidae) from the East Coast of Australia. J. Fish Biol. 78, 2026-2051 (2011).

14. Clarke, T. A. The ecology of the scalloped hammerhead shark Sphyrna lewini in Hawaii. Pacific Sci. 25, 133-144 (1971).

15. Castro, J. I. The hammerhead sharks. In The Sharks of North America 504-531 (Oxford University Press, 2011).

16. Smith, W. D., Miller, J. A. \& Heppell, S. S. Elemental markers in elasmobranchs: effects of environmental history and growth on vertebral chemistry. PLoS One 8, e62423 (2013).

17. Scharer, R. M., Patterson, W. F., Carlson, J. K. \& Poulakis, G. R. Age and growth of endangered smalltooth sawfish (Pristis pectinata) verified with LA-ICP-MS analysis of vertebrae. PLoS One 7, e47850 (2012).

18. Pistevos, J. C. A., Reis-Santos, P., Izzo, C. \& Gillanders, B. Element composition of shark vertebrae shows promise as a natural tag. Mar. Freshw. Res (2019)

19. Tillett, B. J. et al. Decoding fingerprints: Elemental composition of vertebrae correlates to age-related habitat use in two morphologically similar sharks. Mar. Ecol. Prog. Ser. 434, 133-142 (2011).

20. Mohan, J. A. et al. Elements of time and place: manganese and barium in shark vertebrae reflect age and upwelling histories. Proc. $R$. Soc. London, Biol. Sci. 285, 1-7 (2018).

21. Carlisle, A. et al. Stable isotope analysis of vertebrae reveals ontogenetic changes in habitat in an endothermic pelagic shark. Proc. $R$. Soc. London, Biol. Sci. 282 (2014).

22. Estrada, J. A., Rice, A. N., Natanson, L. J. \& Skomal, G. B. Use of isotopic analysis of vertebrae in reconstructing ontogenetic feeding ecology in white sharks. Ecology 87, 829-834 (2006).

23. Smith, W. D., Miller, J. A., Márquez-Farías, J. F. \& Heppell, S. S. Elemental signatures reveal the geographic origins of a highly migratory shark: prospects for measuring population connectivity. Mar. Ecol. Prog. Ser. 556, 173-193 (2016).

24. Lewis, J. P., Patterson, W. F., Carlson, J. K. \& McLachlin, K. Do vertebral chemical signatures distinguish juvenile blacktip shark (Carcharhinus limbatus) nursery regions in the northern Gulf of Mexico? Mar. Freshw. Res. 67, 1014-1022 (2016).

25. McMillan, M. N. et al. Analysis of vertebral chemistry to assess stock structure in a deep-sea shark, Etmopterus spinax. ICES J. Mar. Sci. 64, 793-803 (2016).

26. McMillan, M. N., Huveneers, C., Semmens, J. M. \& Gillanders, B. M. Natural tags reveal populations of Conservation Dependent school shark use different pupping areas. Mar. Ecol. Prog. Ser. 599, 147-156 (2018).

27. Izzo, C. et al. Vertebral chemistry demonstrates movement and population structure of bronze whaler. Mar. Ecol. Prog. Ser. 556, 195-207 (2016).

28. Raoult, V. et al. Strontium mineralization of shark vertebrae. Sci. Rep. 6, 29698 (2016).

29. Allen, P. J., Hobbs, J. A., Cech, J. J., Van Eenennaam, J. P. \& Doroshov, S. I. Using trace elements in pectoral fin rays to assess life history movements in sturgeon: estimating age at initial seawater entry in Klamath river green sturgeon. Trans. Am. Fish. Soc. 138, $240-250$ (2009) 
30. Ranaldi, M. M. \& Gagnon, M. M. Trace metal incorporation in otoliths of black bream (Acanthopagrus butcheri Munro), an indicator of exposure to metal contamination. Water. Air. Soil Pollut. 194, 31-43 (2008).

31. Ranaldi, M. M. \& Gagnon, M. M. Trace metal incorporation in otoliths of pink snapper (Pagrus auratus) as an environmental monitor. Comp. Biochem. Physiol. Part C Toxicol. Pharmacol. 152, 248-255 (2010).

32. Selleslagh, J. et al. Can analysis of Platichthys flesus otoliths provide relevant data on historical metal pollution in estuaries? Experimental and in situ approaches. Sci. Total Environ. 557-558, 20-30 (2016).

33. Wourms, J. P. Reproduction and development in chondrichthyan fishes. Am. Zool. 17, 379-410 (1977).

34. Castro, J. I. A primer on shark reproduction. In The Sharks of North America 533-546 (Oxford University Press, 2011).

35. Pérez-Jiménez, J. C. et al. Artisanal shark fishery at 'Tres Marias' Islands and Isabel Island in the Central Mexican Pacific. J. Northwest Atl. Fish. Sci. 35, 333-343 (2005).

36. Alejo-Plata, M. C., Ramos Carrillo, S. \& Cruz Ruiz, J. L. La pesquería artesanal del tiburón en Salina Cruz, Oaxaca, México. Cienc. y Mar X, 37-51 (2006).

37. Mendizábal-Oriza, D., Vélez-Marín, R., Soriano-Velásquez, S. \& González-Ania, V. Tiburones oceánicos del Pacífico mexicano. In Sustentabilidad y Pesca Responsable en México, 1999-2000 (eds. Cisneros Mata, M. A. \& Díaz de León, A. J.) (INP-SAGARPA, 2002).

38. Schroeder, R. Utilisation of vertebral microchemistry techniques to determine population structure of two inshore shark species along the east coast of Queensland, Australia. (James Cook University, 2011).

39. Jones, D. L., Switzer, T. S., Houston, B. \& Peebles, E. B. Use of otolith microchemistry to improve fisheries-independent indices of recruitment for gag (Mycteroperca microlepis): Linking estuarine nurseries to nearshore reefs in the eastern Gulf of Mexico. SEDAR33-DW09 (2013)

40. Zolfonouna, E., Pakzada, S. M. R. \& Salahinejad, M. Determination of 137Ba Isotope Abundances in Water Samples by Inductively Coupled Plasma-optical Emission Spectrometry Combined with Least-squares Support Vector Machine Regression. Anal. Bioanal. Chem. 3, 65-72 (2016).

41. Marie, A. D., Miller, C., Cawich, C., Piovano, S. \& Rico, C. Fisheries-independent surveys identify critical habitats for young scalloped hammerhead sharks (Sphyrna lewini) in the Rewa Delta, Fiji. Sci. Rep. 7, 1-12 (2017).

42. Brown, K. T., Seeto, J., Lal, M. M. \& Miller, C. E. Discovery of an important aggregation area for endangered scalloped hammerhead sharks, Sphyrna lewini, in the Rewa River estuary, Fiji Islands. Pacific Conserv. Biol. 22, 242 (2016).

43. Duncan, K. M. \& Holland, K. N. Habitat use, growth rates and dispersal patterns of juvenile scalloped hammerhead sharks Sphyrna lewini in a nursery habitat. Mar. Ecol. Prog. Ser. 312, 211-221 (2006).

44. Amezcua, F., Ramirez, M. \& Flores-Verdugo, F. Classification and comparison of five estuaries in the southeast Gulf of California based on environmental variables and fish assemblages. Bull. Mar. Sci. 95, 139-159 (2019).

45. McCulloch, M., Cappo, M., Aumend, J. \& Müller, W. Tracing the life history of individual barramundi using laser ablation MC-ICPMS Sr-isotopic and Sr/Ba ratios in otoliths. Mar. Freshw. Res. 56, 637-644 (2005).

46. Crook, D. A., Macdonald, J. I., O’Connor, J. P. \& Barry, B. Use of otolith chemistry to examine patterns of diadromy in the threatened Australian grayling Prototroctes maraena. J. Fish Biol. 69, 1330-1344 (2006).

47. Pearce, N. J. G. et al. A Compilation of New and Published Major and Trace Element Data for NIST SRM 610 and NIST SRM 612 Glass Reference Materials. Geostand. Geoanalytical Res. 21, 115-144 (1997).

48. Koenig, A. E. \& Wilson, S. A. A marine carbonate reference material for microanalysis. In Proceedings of the First International Sclerochronology Conference, St. Petersburg, Florida, July 17-21, 2007 (2007).

49. Breiman, L. \& Cutler, A. Manual on setting up, using, and understanding Random Forests v4.0. Technical Report. Available from, http://www.stat.berkeley.edu/breiman/Using_random_forests_v4.0.pdf (2003).

50. Anderson, M. J., Walsh, D. C. I., Robert Clarke, K., Gorley, R. N. \& Guerra-Castro, E. Some solutions to the multivariate Behrens-Fisher problem for dissimilarity-based analyses. Aust. New Zeal. J. Stat. 59, 57-79 (2017).

51. Anderson, M. J. \& Willis, T. J. Canonical Analysis of Principal Coordinates: A Useful Method of Constrained Ordination for Ecology. Ecology 84, 511-525 (2003).

52. White, J. W. \& Ruttenberg, B. I. Discriminant function analysis in marine ecology: some oversights and their solutions. Mar. Ecol. Prog. Ser. 329, 301-305 (2007).

53. Sinclair, D. J., Kinsley, L. P. J. \& Mcculloch, M. T. High resolution analysis of trace elements in corals by laser ablation ICP-MS. Geochim. Cosmochim. Acta 62, 1889-1901 (1998).

54. Francis, R. I. C. C. Back-calculation of fish length: a critical review. J. Fish Biol. 36, 883-902 (1990).

55. Coiraton, C. et al. Periodicity of the growth-band formation in vertebrae of juvenile scalloped hammerhead shark Sphyrna lewini from the Mexican Pacific Ocean. J. Fish Biol. 95, 1072-1085 (2019).

56. Quist, M. C. \& Isermann, D. A. Age and growth of fishes: principles and techniques. Age and growth of fishes: principles and techniques (American Fisheries Society, 2017).

57. Branstetter, S. Age, growth and reproductive biology of the silky shark, Carcharhinus falciformis, and the scalloped hammerhead, Sphyrna lewini, from the northwestern Gulf of Mexico. Environ. Biol. Fishes 19, 161-173 (1987).

58. Ricker, W. E. Growth rates and models. In Fish physiology. Vol. 8. (eds. Hoar, W. S. \& Randal, B. J.) 678-744 (Academic Press, New York, 1979).

59. Jones, D. L. Fathom Toolbox for Matlab: software for multivariate ecological and oceanographic data analysis. College of Marine Science, University of South Florida, St. Petersburg, FL, USA, https://www.marine.usf.edu/research/matlab-resources/ (2017).

60. Lyons, K. \& Adams, D. H. Maternal offloading of organochlorine contaminants in the yolk-sac placental scalloped hammerhead shark (Sphyrna lewini). Ecotoxicology 24, 553-562 (2015).

61. Borga, K., Fisk, A. T., Hoekstra, P. F. \& Muir, D. C. G. Bioaccumulation and trophic transfer of persistent organochlorine contaminants in Arctic marine food webs. Environ. Toxicol. Chem. 23, 2367-2385 (2004).

62. Torres, P., Tristão da Cunha, R., Micaelo, C. \& Dos Santos Rodrigues, A. Bioaccumulation of metals and PCBs in Raja clavata. Sci. Total Environ. 573, 1021-1030 (2016).

63. Soto-Jiménez, M. F. \& Páez-Osuna, F. Distribution and Normalization of Heavy Metal Concentrations in Mangrove and Lagoonal Sediments from Mazatlán Harbor (SE Gulf of California). Estuar. Coast. Shelf Sci. 53, 259-274 (2001).

64. Raygoza-Viera, J. R. et al. Accumulation and distribution of $\mathrm{Hg}$ and $210 \mathrm{~Pb}$ in superficial sediments from a coastal lagoon in the SE Gulf of California associated with urban-industrial and port activities. Environ. Earth Sci. 72, 2729-2739 (2014).

65. Jara-Marini, M. E., Soto-Jiménez, M. F. \& Páez-Osuna, F. Trace metals accumulation patterns in a mangrove lagoon ecosystem, Mazatlán Harbor, southeast Gulf of California. J. Environ. Sci. Heal. Part A 43, 995-1005 (2008).

66. Sturrock, A. M. et al. Physiological influences can outweigh environmental signals in otolith microchemistry research. Mar. Ecol. Prog. Ser. 500, 245-264 (2014).

67. Walther, B. D., Kingsford, M. J., O'Callaghan, M. D. \& McCulloch, M. T. Interactive effects of ontogeny, food ration and temperature on elemental incorporation in otoliths of a coral reef fish. Environ. Biol. Fishes 89, 441-451 (2010).

68. Parsons, D. M. et al. A fisheries perspective of behavioural variability: differences in movement behaviour and extraction rate of an exploited sparid, snapper (Pagrus auratus). Can. J. Fish. Aquat. Sci. 68, 632-642 (2011).

69. Kerr, L. A., Cadrin, S. X. \& Secor, D. H. The role of spatial dynamics in the stability, resilience, and productivity of an estuarine fish population. Ecol. Appl. 20, 497-507 (2010)

70. Chapman, B. B., Brönmark, C., Nilsson, J. ̊. \& Hansson, L. A. The ecology and evolution of partial migration. Oikos 120, 1764-1775 (2011). 
71. Baum, J. K. et al. Sphyrna lewini. The IUCN Red List of Threatened Species 2009: e.T39385A10190088, https://doi.org/10.2305/ IUCN.UK.2007.RLTS.T39385A10190088.en (2007).

72. DOF. NORMA Oficial Mexicana NOM-029-PESC-2006, Pesca responsable de tiburónes y rayas: Especificaciones para su aprovechamiento. 14, 60-102 (Diario Oficial de la Federación, Secretaría de Agricultura, Ganadería, Desarrollo Rural, Pesca y Alimentación, Estados Unidos Mexicanos, 2007).

73. DOF. NORMA Oficial Mexicana NOM-009-SAG/PESC-2015, Que establece el procedimiento para determinar las épocas y zonas de veda para la captura de las diferentes especies de la flora y fauna acuáticas, en aguas de jurisdicción federal de los Estados Unidos Mexica. (Diario Oficial de la Federación, Secretaría de Agricultura, Ganadería, Desarrollo Rural, Pesca y Alimentación, Estados Unidos Mexicanos, 2016).

\section{Acknowledgements}

The first author thanks the Posgrado en Ciencias del Mar y Limnología, UNAM and CONACyT, Mexico for the support during her graduate studies. E.B. Peebles and D.L. Jones provided laboratory facilities, invaluable support and training in LA-ICP-MS analyses at the College of Marine Science, University of South Florida, St. Petersburg, Florida, USA. Many thanks to the artisanal fishers for providing the samples. The authors also gratefully acknowledge the assistance of A. Valencia, M. Cervantes and E. Armenta Valenzuela with sample preparation. Flora pixelia designed schematic illustrations of the scalloped hammerhead shark showed in Fig. 1. H. J. Hartmann and two anonymous reviewers provided valuable revision of this manuscript. The research presented here partially fulfills requirements for the first author's doctoral degree. Funding for this research was provided by CONACyT, the project PAPIIT-IG201215, the Western Division of the American Fisheries Society, the Alianza WWF-Fundación Carlos Slim and partially administered by Pelagios Kakunjá AC.

Author contributions

C.C. and F.A. designed the experiments; C.C. and F.A. collected the samples; C.C. prepared the samples for analyses; C.C. performed the LA-ICP-MS experiments; C.C. analyzed the data; F.A. contributed reagents, materials and analysis tools; C.C. and F.A. wrote the paper.

\section{Competing interests}

The authors declare no competing interests.

\section{Additional information}

Supplementary information is available for this paper at https://doi.org/10.1038/s41598-020-58735-8.

Correspondence and requests for materials should be addressed to F.A.

Reprints and permissions information is available at www.nature.com/reprints.

Publisher's note Springer Nature remains neutral with regard to jurisdictional claims in published maps and institutional affiliations.

(c) (i) Open Access This article is licensed under a Creative Commons Attribution 4.0 International License, which permits use, sharing, adaptation, distribution and reproduction in any medium or format, as long as you give appropriate credit to the original author(s) and the source, provide a link to the Creative Commons license, and indicate if changes were made. The images or other third party material in this article are included in the article's Creative Commons license, unless indicated otherwise in a credit line to the material. If material is not included in the article's Creative Commons license and your intended use is not permitted by statutory regulation or exceeds the permitted use, you will need to obtain permission directly from the copyright holder. To view a copy of this license, visit http://creativecommons.org/licenses/by/4.0/.

(C) The Author(s) 2020 